\section{Obscure gastrointestinal bleeding caused by intestinal lipomatosis: double-balloon endoscopic and laparoscopic views}

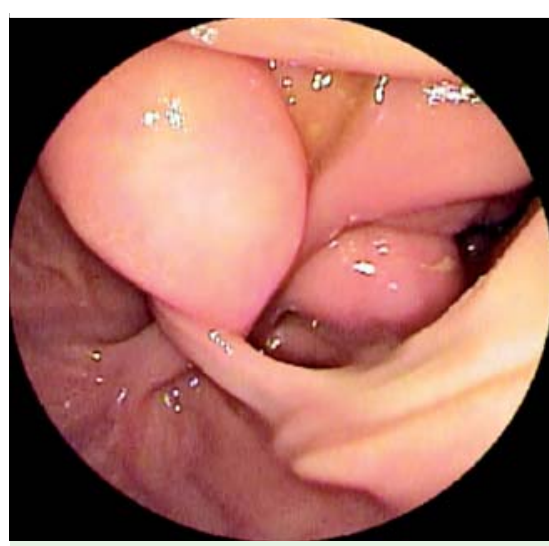

Fig. 1 Double-balloon endoscopy showed small-bowel lipomatosis, with twisted pedunculated lesions located in the distal jejunum.

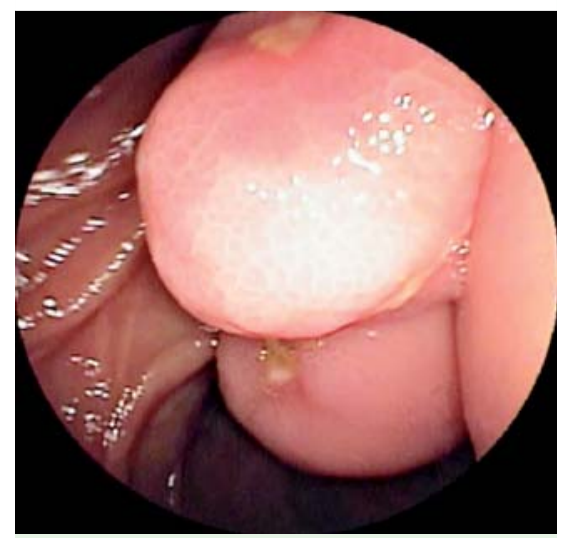

Fig. 2 Pedunculated lesions with signs of ischemia (redness, edema, and apical erosions).

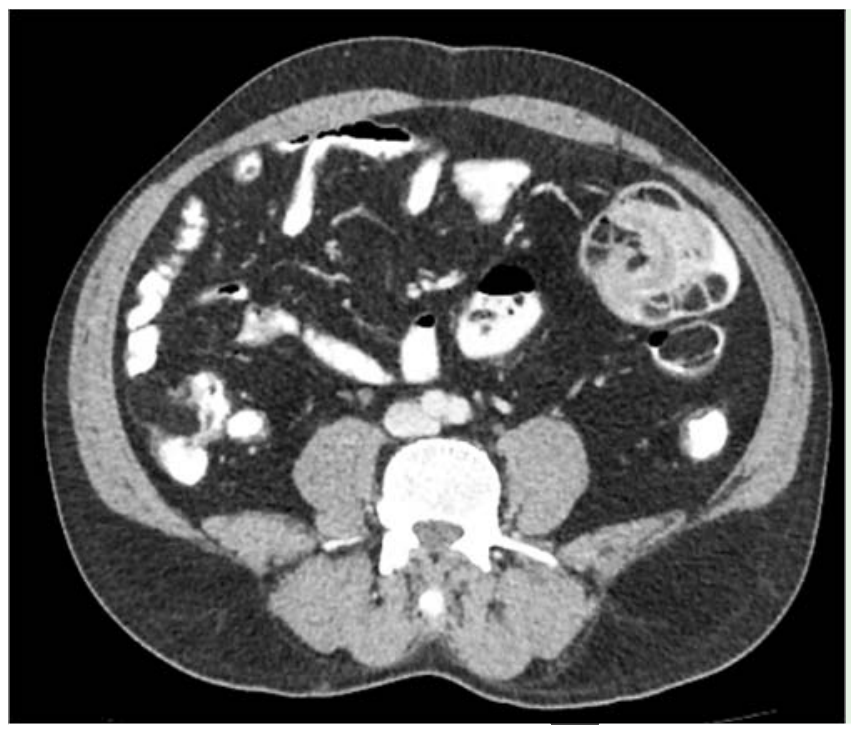

Fig. 3 Abdominal computed tomography scan showing intussusception.

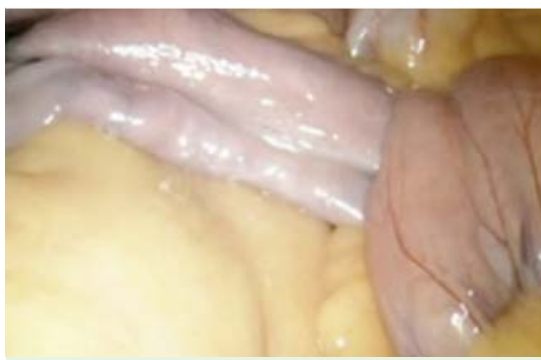

Fig. 4 At laparoscopy, an area of small-bowel intussusception was seen.

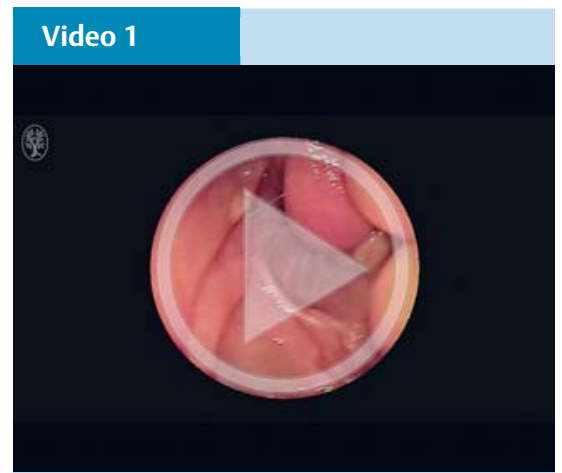
tinal lipomatosis, and laparoscopy, showing small-bowel intussusceptions.
Small-bowel endoscopy, demonstrating intes-
A 52-year-old white man without co-morbidities presented with a 6-year history of recurrent abdominal pain and episodes of melena twice a week for the past year. He was started on oral iron sulfate supplements and had already received a blood transfusion.

Findings from physical examination were normal. The hemoglobin level was $10.8 \mathrm{~g} / \mathrm{dL}$. Gastroduodenoscopy and colonoscopy revealed several smooth sessile and pedunculated lesions covered by normal mucosa, which are characteristics of lipomas, and with no signs of bleeding. Double-balloon endoscopy (DBE) revealed innumerable similar subepithelial lesions, measuring $1-4 \mathrm{~cm}$ in diameter, throughout the entire small bowel ( $\bullet$ Video 1 ). In the distal jejunum, multiple pedunculated lesions were seen, with twisted pedicles, superficial erosion, and covered by fibrin, suggestive of vascular damage ( Fig. 1 , - Fig. 2).

Abdominal computed tomography scan showed multiple hypodense lesions compatible with lipomas, and areas of intussusception with mild proximal smallbowel dilation ( Fig.3). The patient underwent laparoscopy, which confirmed irreducible intussusception, and led to minilaparotomy with four enterotomies and resection of multiple lipomas ( Fig.4, Fig.5). A total of 26 lesions were resected, including some with signs of bleeding. Histopathology confirmed the diagnosis of lipomatosis ( Fig. 6 ).

The patient was discharged 3 days after surgery, and at the 5-month follow-up visit he remained asymptomatic with a hemoglobin level of $12.9 \mathrm{~g} / \mathrm{dL}$.

Lipomas of the gastrointestinal (GI) tract are benign tumors and are usually solitary; however, they can rarely present as GI lipomatosis [1]. Although mostly asymptomatic, GI lipomas may cause symptoms, including obstruction as a result of intussusceptions, and GI bleeding [2,3]. Treatment consists of surgical or endoscopic resection. Endoscopic options include mucosal or submucosal resection, unroofing technique, and application of an endoloop or endoclip $[4,5]$.

This case demonstrated the endoscopic and laparoscopic characteristics of diffuse GI lipomatosis. DBE was essential to the diagnosis, and surgical resection resolved the intussusception and obscure GI bleeding.

Endoscopy_UCTN_Code_CCL_1AC_2AC 

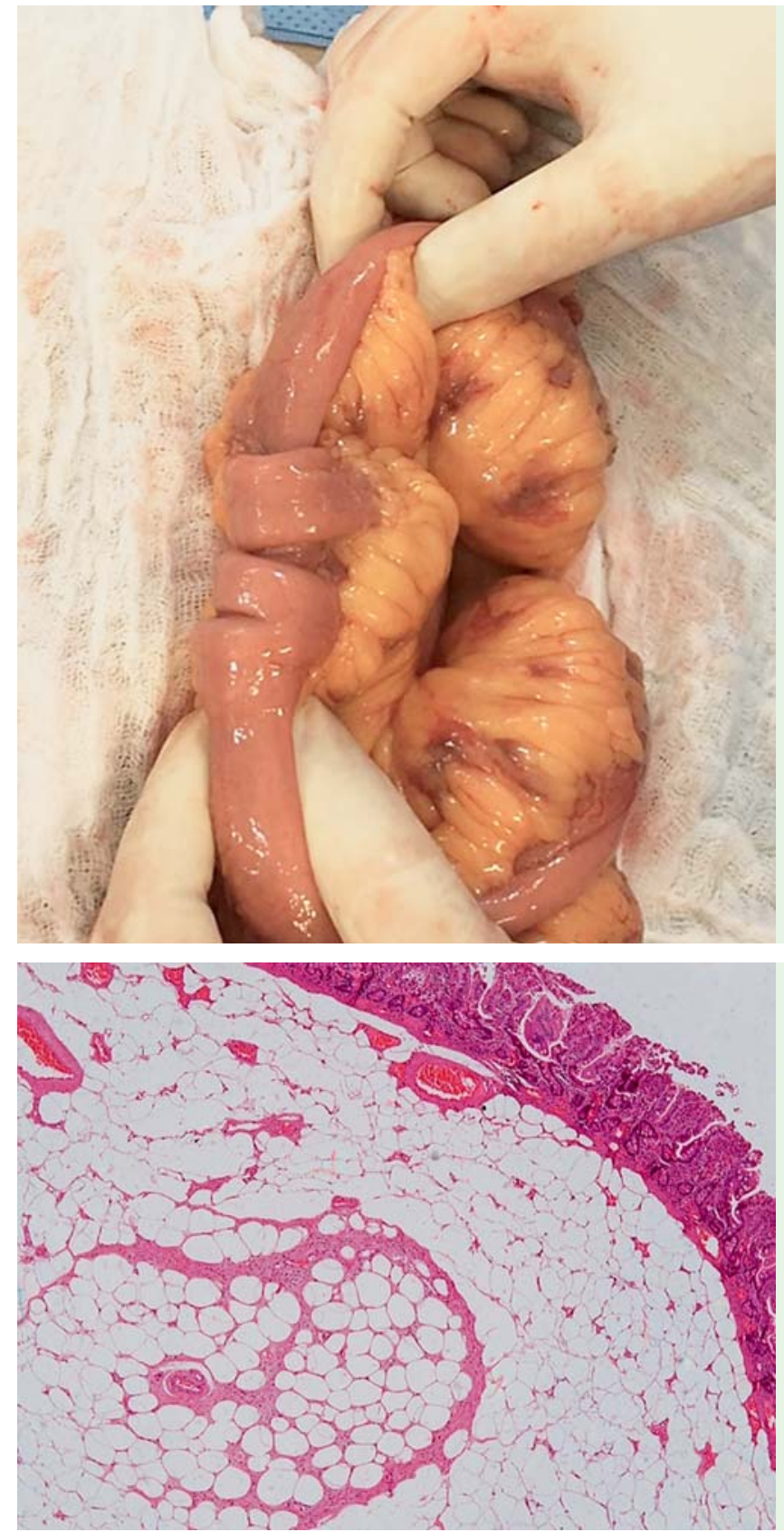

Fig.5 At laparotomy, an area of intussusception was observed.

Fig. 6 Histological analysis of the surgical specimens revealed lipomatosis (hematoxylin and eosin, $\times 10$ ).
Adriana Vaz Safatle-Ribeiro' ${ }^{1}$, Rodrigo

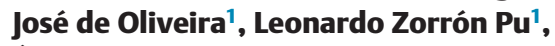
Ângela H. M. Caiado ${ }^{2}$, Eduardo G. H. de Moura ${ }^{1}$, Ulysses Ribeiro ${ }^{1}$, Bruno Zilberstein ${ }^{1}$

${ }^{1}$ Department of Gastroenterology, University of São Paulo Medical School, São Paulo, Brazil

2 Department of Radiology, University of São Paulo Medical School, São Paulo, Brazil

\section{References}

1 Tani T, Abe H, Tsukada $\mathrm{H}$ et al. Lipomatosis of the ileum with volvulus: report of a case.Jpn J Surg 1998; 28: 640-642

2 Gao PJ, Chen L, Wang FS et al. Ileo-colonic intussusceptions secondary to small-bowel lipomatosis: a case report. World J Gastroenterol 2014; 20: 2117-2119

3 Tatsuguchi A, Fukuda Y, Moriyama $T$ et al. Lipomatosis of the small intestine and colon associated with intussusception in the ileocecal region. Gastrointest Endosc 1999; 49: $118-121$

4 Lee BJ, Park JJ, Joo MK et al. A case of smallbowel intussusception caused by intestinal lipomatosis: preoperative diagnosis and reduction of intussusception with doubleballoon enteroscopy. Gastrointest Endosc 2010; 71: 1329-1332

5 Fu C-K, Hsieh T-Y, Huang T-Y. Lipomatosis of the small intestine: detection and endoscopic unroofing by single-balloon enteroscopy. Digest Endosc 2013; 25: 84-93

\section{Bibliography}

DOI http://dx.doi.org/

10.1055/s-0042-101387

Endoscopy 2016; 48: E61-E62

(c) Georg Thieme Verlag KG

Stuttgart · New York

ISSN 0013-726X

\section{Corresponding author}

Adriana Vaz Safatle-Ribeiro, MD, PhD

Department of Gastroenterology

Prédio dos Ambulatórios - Hospital das Clínicas

University of São Paulo Medical School

Av. Dr Enéas de Carvalho Aguiar, 155

$6^{\circ}$ andar, Bloco 3

São Paulo - SP 05403-000

Brazil

Fax: +55-11-2661-7579

adrisafatleribeiro@terra.com.br 